\title{
A CHRYSOPID LARVA THAT CLOAKS ITSELF IN MEALYBUG WAX ${ }^{1}$
}

\author{
By Thomas EisNer and Robert E. Silberglied ${ }^{2}$ \\ Section of Neurobiology \& Behavior, \\ Cornell University, Ithaca NY 14853
}

While doing field work on Lignumvitae Key, Monroe County, Florida, on May 18-20, 1974, we noted a widespread mealybug infestation, on the underside of leaves of a shrub of the genus Eugenia (family Myrtaceae). The colonies, which sometimes extended over entire branches of the plant, were easily detectable from a distance by the white waxy covering of the mealybugs. Close inspection showed the mealybugs to be of unusual appearance, and to be associated with a chrysopid predator that seemed itself to be cloaked in wax.

The mealybug turned out to be undescribed. Discovered independently by Miller and Denno (1977), it was assigned to a new genus by these authors and named Plotococcus eugeniae. The holotype is from a series we collected at our Lignumvitae site. The main features of $P$. eugeniae are evident from Figure 1A. Most conspicuous are the long lateral wax filaments, present in mature and developing females, which impart upon these forms a distinct stellate appearance. Younger individuals, including "crawlers," which have fewer and shorter filaments, are often partly hidden beneath the overlapping filaments of females. Microscopic examination of filaments showed these to consist of central shafts, densely beset with powdery wax (Fig. 2). The surface of infested leaves typically bore a loose coating of this wax.

The chrysopid, camouflaged by the wax packet on its back (Fig. 1B, C), had initially escaped our detection. We eventually learned to spot it at close range, by the oval shape of its packet, and its occasional mobility. It proved surprisingly abundant. We located dozens of individuals amidst the mealybugs in a few hours of observation.

'Paper no. 85 of the series Defense Mechanisms of Arthropods.

${ }^{2}$ Deceased, January 13, 1982.

Manuscript received by the editor March 9, 1988. 

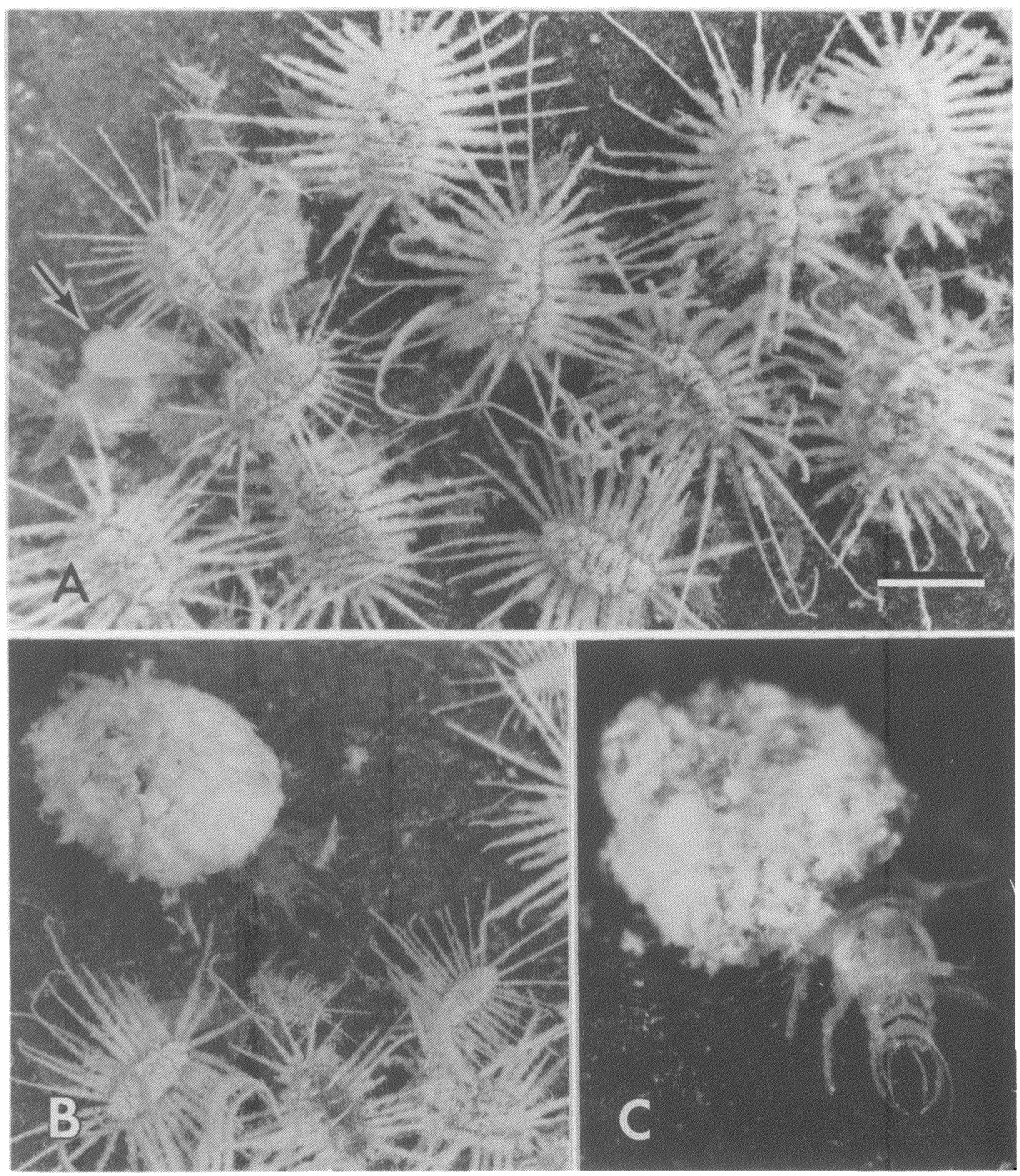

Fig. 1. A, Detail of colony of Plotococcus eugeniae. The large stellate individuals are females. A winged male is denoted by the arrow. B, Last instar larva of Ceraeochrysa cincta amidst its prey. C, Same, enlarged view (Bar in $A=1 \mathrm{~mm}$ ).

Pupal cocoons were present as well, as were typical stalked chrysopid eggs, on or near the infested leaves. The cocoons were themselves white from wax incorporated into their case, and therefore well camouflaged when located near mealybugs. We succeeded in raising over two dozen adults, some from pupae, others from young larvae. All were identified as Ceraeochrysa cincta (voucher material deposited in the Cornell University insect collection, lot no. 1164). 
Closeup observation of $C$. cincta larvae that we took with colonies of Plotococcus to a laboratory setting (Archbold Biological Station, Lake Placid, Florida) enabled us to determine that the larvae do indeed construct their packets from wax that they pluck from mealybugs. We removed packets from several larvae with forceps, and then observed how they rebuilt their packets when we returned them to their hosts. Most commenced packet construction at once. They approached individual mealybugs, most often filament-bearing females, and grasped one or more of the filaments with their curved mandibles. They then pulled back, grasping a load of wax powder in the process, together with occasional filaments that became detached. Finally they flexed the head sharply over the abdomen, and deposited the load directly on their back. They often arched the back upward at the same time, so as to bring it within reach of the mandibles. Load after waxy load they sequestered in this fashion, shifting from mealybug to mealybug as they plucked away, until their packet was complete. At times they supplemented their gatherings with scoopings of wax and debris from the leaf surface, but mealybug wax seemed to take priority for all larvae.

In feeding, the chrysopids seemed to prefer the younger stages of the mealybug. They consumed mostly "crawlers" and other early instars, and appeared to avoid the larger filament-bearing forms. We did not observe chrysopids adding sucked-out prey remains to their dorsal packets, perhaps because such packets were already fully formed in individuals we noted feeding. Packets that we had removed from individuals used in the reloading tests, when teased apart, did show presence of whole-mealybug remains.

Ceraeochrysa cincta is evidently a "trash-carrier," a member of that large group of chrysopids whose larvae all build dorsal packets from exogenous materials, including vegetable matter, arthropod remains, and general debris (DeWitz, 1885; Killington 1936, 1937; Slocum and Lawrey, 1976; Smith, 1922). Use of homopteran wax for packet construction is not without precedent. Chrysopa slossonae, an obligate predator of the wooly alder aphid, Prociphilus tesselatus, plucks wax from its prey and builds a dense shield from this material, which protects it against ants (Eisner et al., 1978). $C$. cincta may be similarly protected by its packet, possibly against other predators as well. The camouflage itself, by reducing conspicuousness to visually oriented predators, including perhaps birds, which might be expected to ignore mealybugs, could provide a first line of defense. 


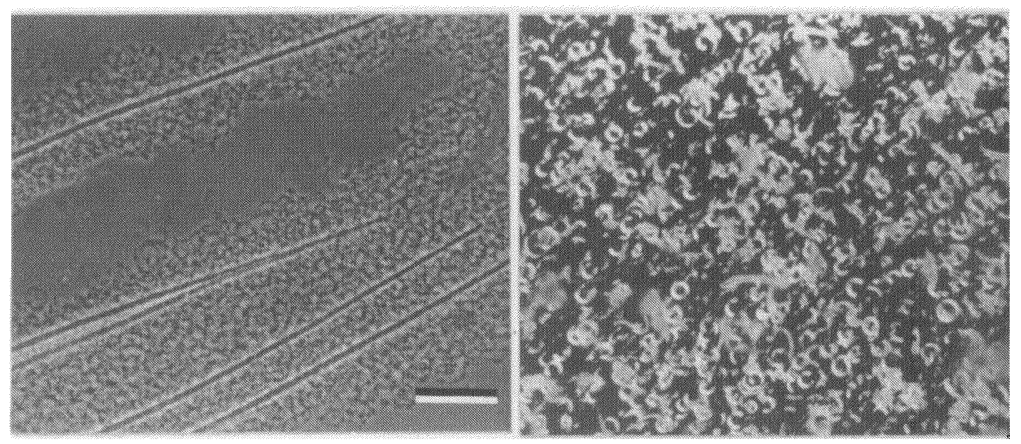

Fig. 2. Left; wax filaments of Plotococcus eugeniae. Note loose coating of wax powder on the central shafts (Phase microscopy). Right; isolated particles of wax powder (Dark Field microscopy). (Bar on left, valid for both $=50 \mu \mathrm{m}$ ).

We observed two additional chrysopid predators in the Plotococcus colonies, both less numerous than $C$. cincta, as well as one abundant syrphid fly larva. One of the chrysopids, which we succeeded in raising, proved to be Chrysopodes collaris. The syrphid, which we also raised, was identified as Ocyptamus parvicornis.

Preliminary chemical work by H. M. Fales and R. T. Mason at the National Institutes of Health, Bethesda, Maryland, showed the $P$. eugeniae wax to consist of a mixture of triglycerides of even-numbered $\left(\mathrm{C}_{10}\right.$ to $\left.\mathrm{C}_{18}\right)$ fatty acids.

\section{POSTSCRIPT AND ACKNOWLEDGMENTS}

We had initially hoped to undertake an in-depth study of Plotococcus and its associates, a plan that was thwarted by the tragic death of Robert E. Silberglied. The present paper, written by the senior author, is based on notes taken jointly with Dr. Silberglied. For identification of the chrysopids and syrphid, we are indebted, respectively, to Philip Adams (California State University, Fullerton) and F. Christian Thompson (U.S. National Museum of Natural History). We thank the staff of the Archbold Biological Station, Lake Placid, Florida, for hospitality during our stay. Maria Eisner prepared the illustrations.

\section{REFERENCES}

DeWitz, H.

1885. Die Angelhaare der Chrysopenlarven. Biologisches Centralblatt 4: 722-723. 
EISNER, T., K. Hicks, M. EISNER, AND S. D. RobSON

1978. "Wolf-in-sheep's-clothing" strategy of a predaceous insect larva. Science 199: 790-794.

Killington, F. J.

1936. A monograph of the British Neuroptera, v. 1. London: The Ray Society.

1937. A monograph of the British Neuroptera, v. 2. London: The Ray Society.

Miller, D. R. AND R. F. DenNo

1977. A new genus and species of mealybug with a consideration of morphological convergence in three arboreal species (Homoptera: Pseudococcidae). Systematic Entomology 2: 111-157.

Slocum, R. D. AND J. D. LaWrey

1976. Viability of the epizoic lichen flora carried and dispersed by green lacewing (Nodita pavida) larvae. Candian Journal of Botany 54: 1827-1831.

SмITH, R. C.

1922. The biology of the Chrysopidae. Memoirs of the Cornell University Agricultural Experiment Station 58: 1286-1376. 

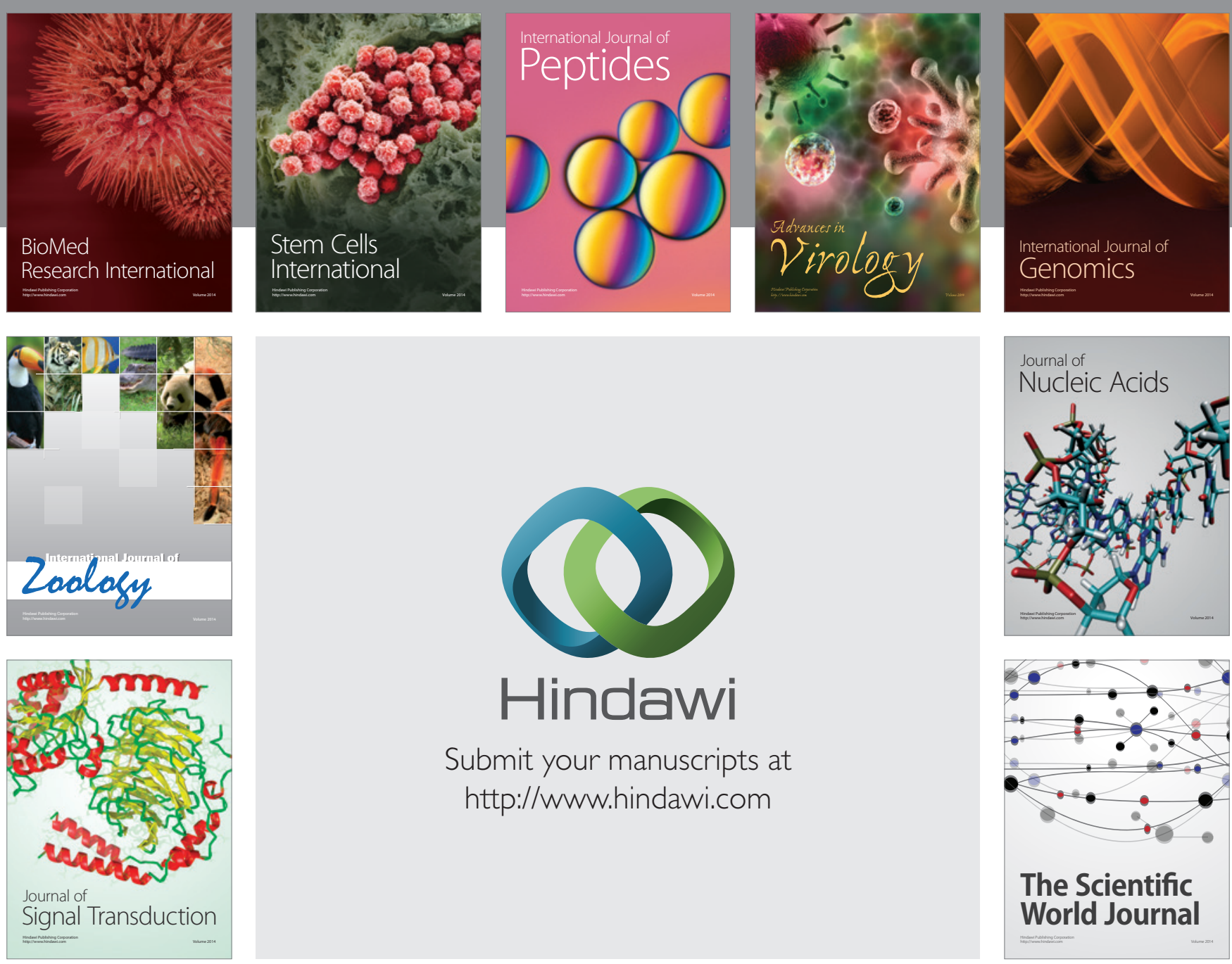

Submit your manuscripts at

http://www.hindawi.com
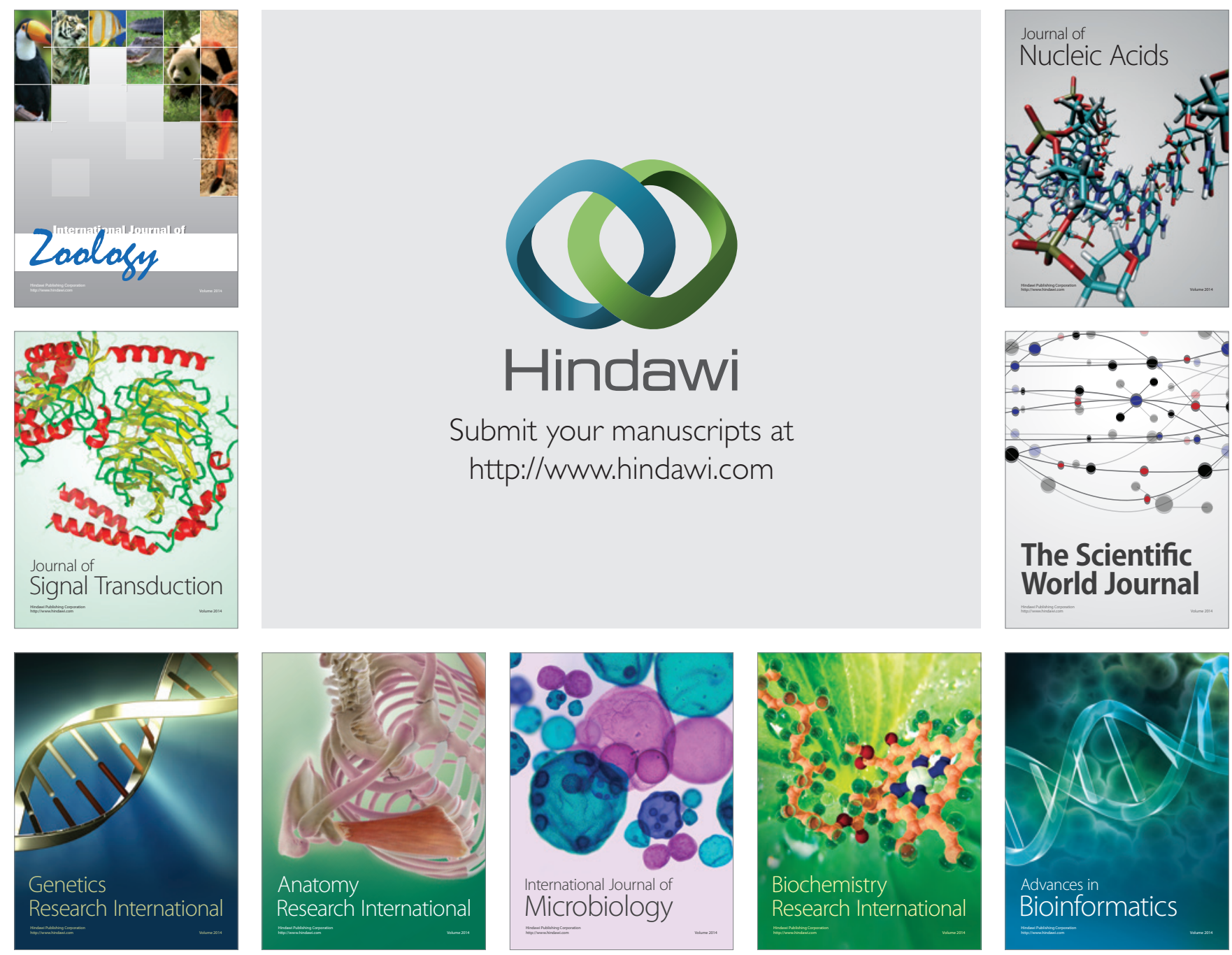

The Scientific World Journal
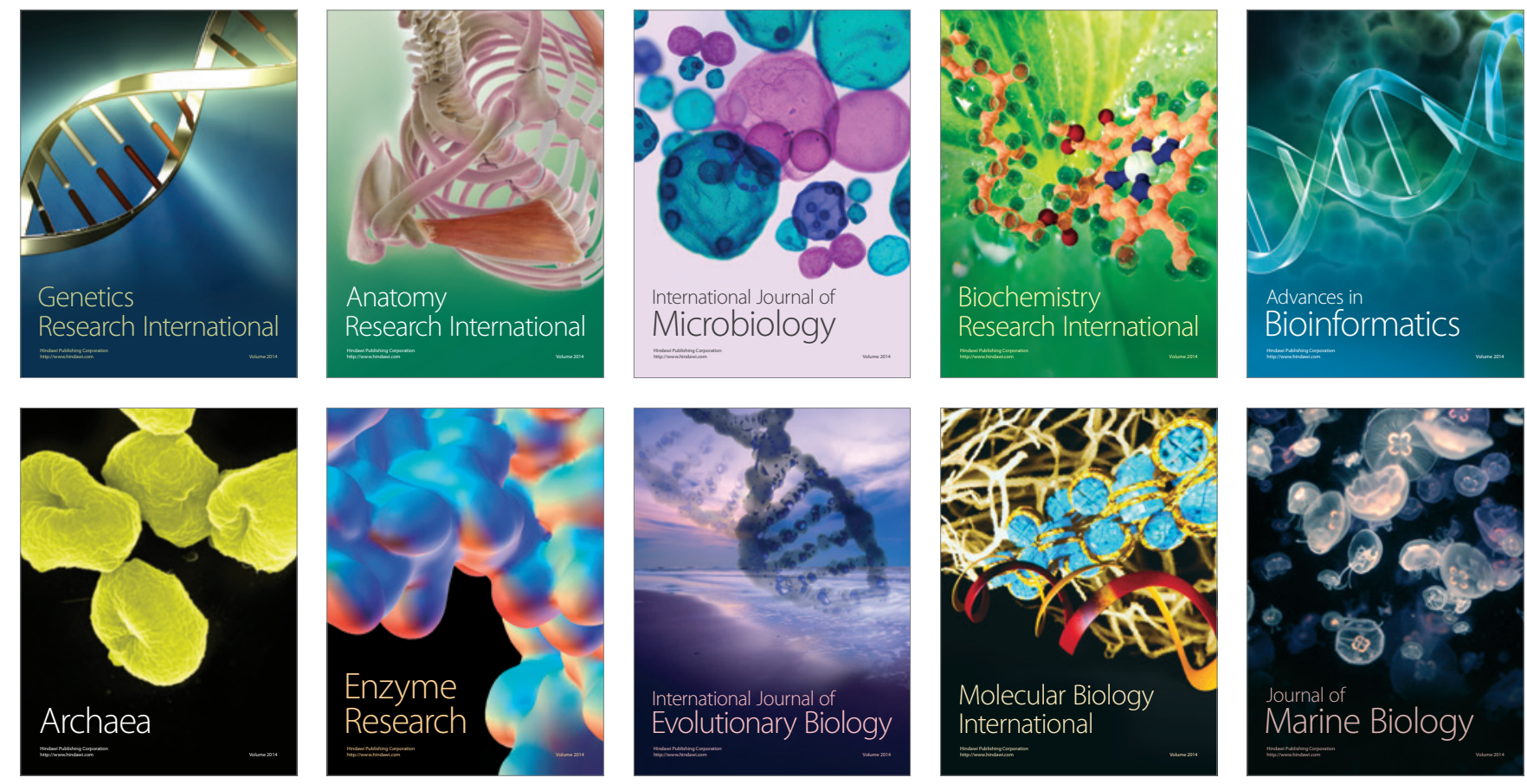